\title{
Prediction of Indian Monsoon Rainfall by Interval based Simplified High Order Fuzzy Time Series Model \\ Amit Kumar Rana
}

\begin{abstract}
Rain is of uttermost importance for agriculture based economies. Most of the Asian countries, India in particular largely depend on a good rainfall. The prediction of rainfall will not only help government to make better future policies but also farmers and agro based companies can make better future management. Rainfall forecasting involves high degree of uncertainty and for such conditions fuzzy time series and other soft computing techniques are best to deal with. The utility of a forecasting method lies with the accuracy with the predicted values. In this paper rainfall prediction by fuzzy time series model is proposed in which two difference values of the interval corresponding to the fuzzified forecasted value is proposed. This model is tested on real time data of average monsoon rainfall in India. The predicted values are compared with Chen model. The results show that the proposed model have less error compared to Chen's model.
\end{abstract}

Keywords: Difference intervals, Fuzzy relations (FR), Fuzzy sets (FS), Fuzzy time series model (FTSM)

\section{INTRODUCTION}

Zadeh [5] was first to consider the uncertainty in mathematical formulations and presented FS theory. Since then FS become one of the best techniques in dealing with the daily life problems having vagueness and uncertainty in the information. Song and Chissom [8], [9] successfully implemented the idea of verbal variables for approximate reasoning using FTSM and applied it on Alabama University's enrollment data. Huarng [4] model improved the forecast of university enrollments using heuristic increasing and decreasing relation and tested this model on Taiwan Futures Exchange forecasting. Chen [10] used arithmetic operations instead of completed max-min operators and presented high order FTSM and got better results than Song and Chissom [8], [9]. Chen and Hsu [11] developed a new improved FTS method for forecasting enrollments. Optimal length of interval is the base for a good forecasting model. Singh [7] presented a review in which FTS based modeling techniques are discussed. Rana [1] studied on the rice production FTS Forecasting model. Panigrahi and Behera [12] in his study proposed an efficient computational model for forecasting using high order FTS. Rana [2] worked on time invariant models and presented a comparative study for forecasting crop production using time invariant FTS models. Chen [3] et al. used an important

Revised Manuscript Received on April 04, 2020.

Amit Kumar Rana*, Assistant Professor, Department of Mathematics, Swami Vivekanand Subharti University, Meerut, Uttar Pradesh, India, Email: akrana77@gmail.com

(C) The Authors. Published by Blue Eyes Intelligence Engineering and Sciences Publication (BEIESP). This is an open access article under the CC BY-NC-ND license (http://creativecommons.org/licenses/by-nc-nd/4.0/) common problem of many countries and proposed a model for real time flood forecasting by FTSM. Bose and Mali [6] presented a survey on designing FTSM which provides a base for studying this soft computing technique. The proposed model uses a high order FTSM for forecasting a Indian monsoon rainfall using a 15 years historical data of rainfall from meteorological department of government of India.

\section{PRELIMINARIES OF FS}

Definition 1. FS $A_{i}$ with membership function $\mu_{A_{i}}$ on $U=\left\{u_{1}, u_{2}, u_{3} \ldots . u_{n}\right\}$ is defined by

$$
\begin{gathered}
A_{i}=\frac{\mu_{A_{1}}\left(u_{1}\right)}{u_{1}}+\frac{\mu_{A_{2}}\left(u_{2}\right)}{u_{2}}+\frac{\mu_{A_{2}}\left(u_{2}\right)}{u_{2}}+\cdots \\
+\frac{\mu_{A_{n}}\left(u_{n}\right)}{u_{n}}
\end{gathered}
$$

Definition 2. Let FS $f_{i}(t),(i=1,2,3 \ldots)$ are defined on $Y(t)$ and $F(t)$ is the collection of all $f_{i}$ then $F(t)$ is called FTS on $Y(t)$.

Definition 3. Suppose $F(t)$ is caused only by $F(t-1)$ and is denoted by $F(t-1) \rightarrow F(t) \Rightarrow$ a fuzzy relationship between $F(t)$ and $F(t-1)$ and $F(t)$ is caused only by $F(t-1)$. This can be expressed by the fuzzy relational equation: $F(t)=F(t-1) o R(t, t-1)$ where, " $o$ "' is MaxMin composition operator. Relation $R$ is called model firstorder of $F(t)$.Also if $R\left(t_{1}, t_{1}-1\right)=R\left(t_{2}, t_{2}-1\right), \forall t_{1} \neq$ $t_{2}$ then $F(t)$ is called a time invariant FTS.

Definition 4. A $n^{\text {th }}$-order FTS is one in which $F(t)$ is caused by $n$ fuzzy sets $F(t-n), F(t-n+1), \ldots F(t-1)$ and the fuzzy relationship is given by $A_{i_{1}}, A_{i_{2}}, A_{i_{3}} \ldots \ldots \ldots . A_{i_{n}} \rightarrow A_{j}$

Here, $\quad F(t-n)=A_{i_{1}}, \ldots \ldots \ldots \ldots \ldots \ldots(t-1)=A_{i_{n}}$

\section{PROPOSED METHODOLOGY}

Step 1. Define $U$ as $U=\left[U_{\min }-U_{1}, U_{\max }-U_{2}\right]$ where $U_{1}$ and $U_{2}$ are two proper positive numbers and $U_{\min }, U_{\max }$ are min. and max. values of real time rainfall data respectively.

Step 2. Construct equal length sub intervals $u_{1}, u_{2}, \ldots \ldots . u_{m}$ from.

Step 3. Construct the FS $A_{i}$

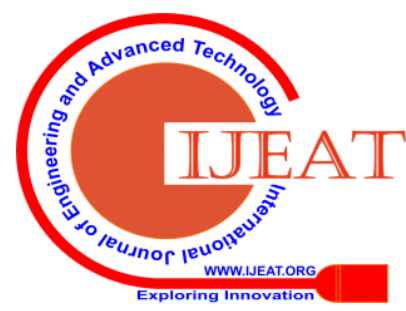


Step 4. Fuzzify the data and establish FLR using If $A_{c}, A_{n}$ are the fuzzy production for $n^{\text {th }},(n+1)^{\text {th }}$ year then FLR is $A_{c} \rightarrow A_{n}$ where $A_{c}, A_{n}$ are called current and next state. Step 5. Using FLR, obtain fuzzified output.

Step 6. defuzzified and obtained the forecasted value using $\left[S_{n}{ }^{*}\right] \quad$ is corresponding interval $u_{n}$ for which $A_{n}$ has max. membership 1

$L\left[S_{n}{ }^{*}\right] \quad$ lower bound of $u_{n}, \quad U\left[S_{n}{ }^{*}\right] \quad$ upper bound of $u_{n}$

$l\left[S_{n}{ }^{*}\right] \quad$ length of $u_{n}$, $M\left[S_{n}{ }^{*}\right]$ mid value of $u_{n}$ For FLR $A_{c} \rightarrow A_{n}$

$A_{c}$ : $\quad$ fuzzified data of $n^{\text {th }}$ year,

$A_{n}$ : fuzzified data of $(n+1)^{\text {th }}$ year

$E_{c}: \quad$ actual data of $n^{\text {th }}$ year

$E_{c-1}$ : actual data of $(n-1)^{\text {th }}$ year

$E_{c-2}: \quad$ actual data of $(n-2)^{\text {th }}$ year

$F_{n}$ : $\quad$ crisp forecasted value of the $(n+1)^{\text {th }}$ year

Algorithm for forecasting rainfall

FLR for $k^{\text {th }}$ to $(k+1)^{\text {th }}$ year is $A_{c} \rightarrow A_{n} ; k=3$...upto end of time series data

Calculating the differences as

$D_{c}=|| E_{c}-E_{c-1}|-| E_{c-1}-E_{c-2}||$

$\alpha_{c}=E_{c}+\frac{D_{c}}{3} \quad \alpha_{c}^{\prime}=E_{c}-\frac{D_{c}}{3}, \quad \beta_{c}=E_{c}+\frac{2 D_{c}}{3}$

$\beta_{c}^{\prime}=E_{c}-\frac{2 D_{c}}{3}$

$\gamma_{c}=E_{c}+D_{c}$

$$
\gamma_{c}^{\prime}=E_{c}-D_{c}
$$

For $I=1$ to 6

If $L\left[S_{n}{ }^{*}\right] \leq \alpha_{c} \leq U\left[S_{n}{ }^{*}\right]$ then $F_{1}=\alpha_{c}, \mathrm{n}_{1}=1$, Else $F_{1}=0, \mathrm{n}_{1}=0$

Next : If $L\left[S_{n}{ }^{*}\right] \leq \alpha^{\prime}{ }_{c} \leq U\left[S_{n}{ }^{*}\right]$ then $F_{2}=\alpha^{\prime}{ }_{c}, \mathrm{n}_{2}=1$,

Else $F_{2}=0, \mathrm{n}_{2}=0$

Next : If $L\left[S_{n}{ }^{*}\right] \leq \beta_{c} \leq U\left[S_{n}{ }^{*}\right]$ then $F_{3}=\beta_{c}, \mathrm{n}_{3}=1$,

Else $F_{3}=0, \mathrm{n}_{3}=0$

Next : If $L\left[S_{n}{ }^{*}\right] \leq \beta_{c}^{\prime} \leq U\left[S_{n}{ }^{*}\right]$ then $F_{4}=\beta^{\prime}{ }_{c}, \mathrm{n}_{4}=$ 1 , Else $F_{4}=0, \mathrm{n}_{4}=0$

Next : If $L\left[S_{n}{ }^{*}\right] \leq \gamma_{c} \leq U\left[S_{n}{ }^{*}\right]$ then $F_{5}=\gamma_{c}, \mathrm{n}_{5}=1$, Else $F_{5}=0, \mathrm{n}_{5}=0$

Next : If $L\left[S_{n}{ }^{*}\right] \leq \gamma_{c}^{\prime} \leq U\left[S_{n}{ }^{*}\right]$ then $F_{6}=\gamma_{c}^{\prime}, \mathrm{n}_{6}=$ 1 , Else $F_{6}=0, \mathrm{n}_{6}=0$

Now $\Delta=F_{1}+F_{2}+F_{3}+F_{4}+F_{5}+F_{6}$

If $\Delta=0$ then $F_{n}=M\left[S_{n}{ }^{*}\right]$, Else $F_{n}=\left(\Delta+M\left[S_{n}{ }^{*}\right]\right) /$

$\left(\mathrm{n}_{1}+\mathrm{n}_{2}+\mathrm{n}_{3}+\mathrm{n}_{3}+\mathrm{n}_{4}+\mathrm{n}_{5}+\mathrm{n}_{6}+1\right)$

Next $k$

\section{STEPWISE APPLICATION OF THE PROPOSED MODEL}

Step 1. Universe of discourse $U=[0940,1240]$

Step 2. Partitioning $U$ into equal length of sub intervals with mid values as

$\begin{array}{ll}u_{1}=[0940,0960,0980] & u_{2}=[0980,1000,1020] \\ u_{3}=[1020,1040,1060] & u_{4}=[1060,1080,1100] \\ u_{5}=[1100,1120,1140] & u_{6}=[1140,1160,1180] \\ u_{7}=[1180,1200,1220] & u_{8}=[1200,1220,1240]\end{array}$

Step 3. Defining FS $A_{n}, n=1 \ldots 8$ as

$A_{1}$ : Drought situation, $\quad A_{2}$ : Very low rainfall,

$A_{3}$ : Low rainfall,

$A_{5}:$ Good rainfall,

$A_{7}$ : Heavy rainfall,

$A_{4}$ : Average rainfall,

$A_{6}$ : Very good rainfall,

$A_{8}:$ Flood situation

These FS with membership grades are as
$A_{1}=\frac{1}{u_{1}}+\frac{.5}{u_{2}}+\frac{0}{u_{3}}+\frac{0}{u_{4}}+\frac{0}{u_{5}}+\frac{0}{u_{6}}+\frac{0}{u_{7}}+\frac{0}{u_{8}}$

$A_{2}=\frac{.5}{u_{1}}+\frac{1}{u_{2}}+\frac{.5}{u_{3}}+\frac{0}{u_{4}}+\frac{0}{u_{5}}+\frac{0}{u_{6}}+\frac{0}{u_{7}}+\frac{0}{u_{8}}$

$A_{3}=\frac{0}{u_{1}}+\frac{.5}{u_{2}}+\frac{1}{u_{3}}+\frac{.5}{u_{4}}+\frac{0}{u_{5}}+\frac{0}{u_{6}}+\frac{0}{u_{7}}+\frac{0}{u_{8}}$

$A_{4}=\frac{0}{u_{1}}+\frac{0}{u_{2}}+\frac{.5}{u_{3}}+\frac{1}{u_{4}}+\frac{.5}{u_{5}}+\frac{0}{u_{6}}+\frac{0}{u_{7}}+\frac{0}{u_{8}}$

$A_{5}=\frac{0}{u_{1}}+\frac{0}{u_{2}}+\frac{0}{u_{3}}+\frac{.5}{u_{4}}+\frac{1}{u_{5}}+\frac{.5}{u_{6}}+\frac{0}{u_{7}}+\frac{0}{u_{8}}$

$A_{6}=\frac{0}{u_{1}}+\frac{0}{u_{2}}+\frac{.5}{u_{3}}+\frac{0}{u_{4}}+\frac{.5}{u_{5}}+\frac{1}{u_{6}}+\frac{0}{u_{7}}+\frac{0}{u_{8}}$

$A_{7}=\frac{0}{u_{1}}+\frac{0}{u_{2}}+\frac{0}{u_{3}}+\frac{0}{u_{4}}+\frac{0}{u_{5}}+\frac{.5}{u_{6}}+\frac{1}{u_{7}}+\frac{0}{u_{8}}$,

$A_{8}=\frac{0}{u_{1}}+\frac{0}{u_{2}}+\frac{0}{u_{3}}+\frac{0}{u_{4}}+\frac{0}{u_{5}}+\frac{0}{u_{6}}+\frac{.5}{u_{7}}+\frac{1}{u_{8}}$

Step 4. After getting the fuzzified historical time series rainfall data, table 1 gives obtained FLR

Table 1: Fuzzified Rainfall

\begin{tabular}{|c|c|c|}
\hline Year & $\begin{array}{c}\text { Actual } \\
\text { Rainfall }\end{array}$ & $\begin{array}{c}\text { Fuzzified } \\
\text { Rainfall }\end{array}$ \\
\hline 2000 & 1035.4 & $A_{3}$ \\
\hline 2001 & 1105.2 & $A_{5}$ \\
\hline 2002 & 0981.9 & $A_{2}$ \\
\hline 2003 & 1233.6 & $A_{8}$ \\
\hline 2004 & 1080.5 & $A_{4}$ \\
\hline 2005 & 1208.3 & $A_{7}$ \\
\hline 2006 & 1161.6 & $A_{6}$ \\
\hline 2007 & 1179.3 & $A_{6}$ \\
\hline 2008 & 1118.0 & $A_{5}$ \\
\hline 2009 & 0953.7 & $A_{1}$ \\
\hline 2010 & 1215.5 & $A_{7}$ \\
\hline 2011 & 1116.3 & $A_{5}$ \\
\hline 2012 & 1054.7 & $A_{3}$ \\
\hline 2013 & 1092.5 & $A_{4}$ \\
\hline 2014 & 1045.2 & $A_{3}$ \\
\hline
\end{tabular}

Step 5. The forecasted defuzzified rainfall is calculated by using the proposed algorithms and put in the table 2 Step 6. Calculating mean square error (MSE), forecasting error (FE) and average forecasting error (AFE) as

$\operatorname{MSE}=\frac{\sum_{\mathrm{i}=1}^{\mathrm{n}}\left((\text { act. val. })_{\mathrm{i}}-(\text { fore. val. })_{\mathrm{i}}\right)^{2}}{\mathrm{n}}$

$\mathrm{FE}=\frac{\mid \text { act. val }- \text { fore. } \text { val. } \mid}{\text { actual value }} \times 100$

Published By:

Blue Eyes Intelligence Engineering DOI: 10.35940/ijeat.D7527.049420

Journal Website: www.ijeat.org

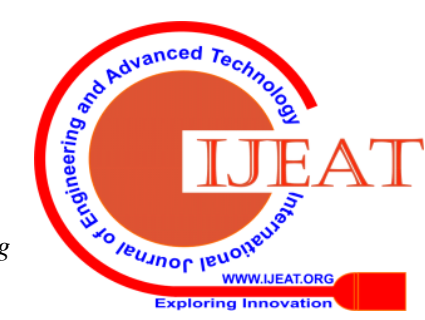


$\mathrm{AFE}=\frac{\text { sum of } \mathrm{FE}}{\text { numbers of errors }} \times 100$

Table 2: Forecasted rainfall

\begin{tabular}{|c|c|c|c|}
\hline Year & $\begin{array}{c}\text { Actual } \\
\text { Rainfall }\end{array}$ & $\begin{array}{c}\text { Forecasted } \\
\text { rainfall } \\
\text { Proposed } \\
\text { Model }\end{array}$ & $\begin{array}{c}\text { Forecasted } \\
\text { rainfall } \\
\text { Chen } \\
\text { Model }\end{array}$ \\
\hline 2000 & 1035.4 & - & - \\
\hline 2001 & 1105.2 & - & 1100 \\
\hline 2002 & 981.9 & - & 1000 \\
\hline 2003 & 1233.6 & 1240.00 & 1240 \\
\hline 2004 & 1080.5 & 1080.00 & 1080 \\
\hline 2005 & 1208.3 & 1200.00 & 1120 \\
\hline 2006 & 1161.6 & 1166.50 & 1140 \\
\hline
\end{tabular}

Figure 1 shows the year wise comparison between actual rainfall and forecasted rainfall by proposed and

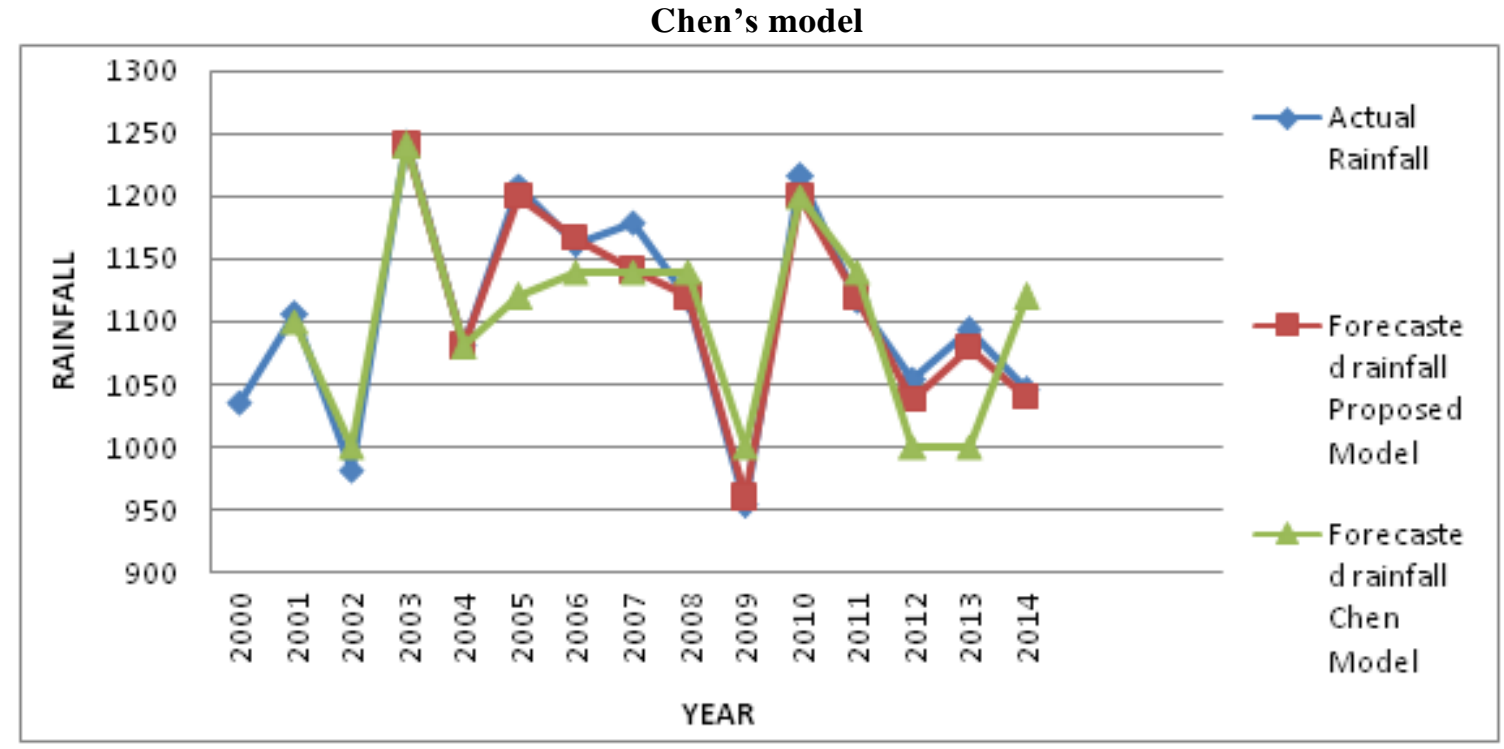

Figure 1: Forecasted and Actual Rainfall

\section{CONCLUSION}

In this paper a new method to predict monsoon rainfall in India is proposed. Rainfall prediction is done by taking values of two differences of the interval corresponding to the fuzzified forecasted value. The proposed method shows significant reduction in the errors of predicted values. Also in the present study the computational procedure is much easier than complicated min-max operation. The robustness of the proposed model is tested on real rainfall data and accuracy of the presented model is verified by comparing the results with Chen's model. The results show betterment in the forecasted values over the compared model.

\section{ACKNOWLEDGEMENT}

The rainfall data taken from website of Indian meteorological department is dully acknowledged.

\begin{tabular}{|c|c|c|c|}
\hline 2007 & 1179.3 & 1140.75 & 1140 \\
\hline 2008 & 1118 & 1120.00 & 1140 \\
\hline 2009 & 953.7 & 0960.00 & 1000 \\
\hline 2010 & 1215.5 & 1200.00 & 1200 \\
\hline 2011 & 1116.3 & 1119.00 & 1140 \\
\hline 2012 & 1054.7 & 1037.50 & 1000 \\
\hline 2013 & 1092.5 & 1078.60 & 1000 \\
\hline 2014 & 1045.2 & 1040.00 & 1120 \\
\hline MSE & - & 199.961 & 2196.344 \\
\hline$\%$ & - & 10.47055 & 46.17992 \\
FE & & 0.872546 & 3.298566 \\
\hline AFE & - & \multicolumn{3}{|c}{} \\
\hline
\end{tabular}

\section{REFERENCES}

1. A.K. Rana, "Rice Production Forecasting Through Fuzzy Time Series", American International Journal of Research in Science, Technology, Engineering \& Mathematics, vol. 23(1), pp. 158-162, 2018.

2. A.K. Rana, "Study on Fuzzy Time Invariant Series Models for Crop Production Forecasting”, International Journal of Scientific Research and Reviews, vol. 8(2), pp. 3729-3741, 2019.

3. C.S. Chen, Y.D. Jhong, W.Z. Wu and S.T. Chen, "Fuzzy Time Series for Real Time Flood Forecasting", Stochastic Environmental Research and Risk Assessment, vol. 33, pp. 645-656, 2019.

4. K. Huarng, "Heuristic Models of Fuzzy Time Series for Forecasting", Fuzzy Sets and Systems, vol. 123, pp. 369-386, 2001.

5. L.A. Zadeh, "Fuzzy sets", Information and Control, vol. 8, pp. 338353, 1965.

6. M. Bose and K. Mali, "Designing Fuzzy Time Series Forecasting Models: A Survey", International Journal of Approximate Reasoning, vol. 111, pp. 78-99, 2019.

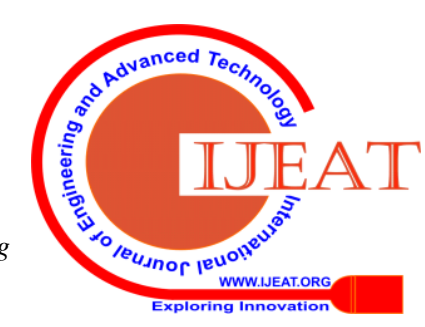


7. P. Singh, “A Brief Review on Modeling Approaches Based on Fuzzy Time Series", International Journal of Machine Learning and Cybernetics, vol. 8(2), pp. 397-420, 2017

8. Q. Song and B. S. Chissom, "Forecasting Enrollments with Fuzzy Time Series - Part I", Fuzzy Sets and Systems, vol. 54, pp. 1-9, 1993

9. Q. Song and B. S. Chissom, "Fuzzy Time Series and Its Models", Fuzzy Sets and Systems, vol.54, pp. 269-277, 1993

10. S.M. Chen, "Forecasting Enrollments Based on High Order Fuzzy Time Series", Cybernetics and Systems: An International Journal, vol. 31, pp. 1-16, 2002

11. S.M. Chen and C.C. Hsu, "A New Method to Forecast Enrollments Using Fuzzy Time Series”, International Journal of Applied Sciences and Engineering, vol. 2(3), pp. 234-244, 2004

12. S. Panigrahi and H.S. Behera, "A Computationally Efficient Method for High Order Fuzzy Time Series Forecasting", Journal of Theoretical and Applied Information Technology, vol. 96(21), pp. 7215-7226, 2018

\section{AUTHOR PROFILE}

Amit Kumar Rana received his M.Sc., Ph.D.

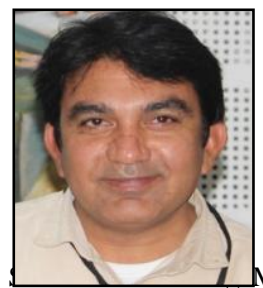

(Mathematics) degree from the G. B. Pant

University of Agriculture \& Technology,

Pantnagar, India in 2000 and 2005 respectively.

During Ph.D. author was a recipient of Junior

Research Fellowship provided by Council of

Scientific and Industrial Research, Govt. of India.

At present he is an Assistant Professor in

Department of Mathematics, Swami Vivekanand

mainly Fuzzy Time techniques.

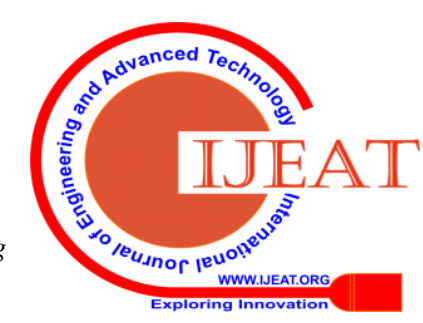

